Spotlight on the May 29 Issue

Robert A. Gross, MD, PhD, FAAN

Editor-in-Chief, Neurology ${ }^{\circledR}$

Mutations in the tail domain of DYNC1H1 cause dominant spinal muscular atrophy

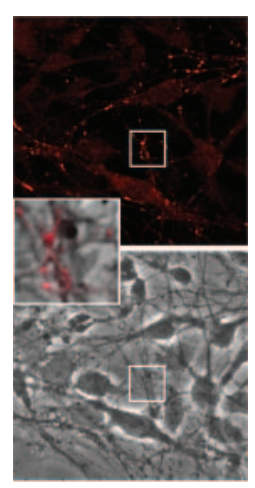

DYNC1H1 mutations were identified in 3 families with a unique dominantly inherited form of spinal muscular atrophy, in some cases with developmental delay. These findings point to dynein, the main motor for retrograde cellular transport, as a central player in developmental and degenerative disorders in the nervous system.

See p. 1714; Editorial, p. 1706

\section{Early thalamic lesions in patients with sleep-potentiated epileptiform activity}

This study compared 100 patients with prominent sleeppotentiated epileptiform activity (PSPEA) with 47 controls. Both groups were comparable in clinical and epidemiologic features. Persons with PSPEA have a higher frequency of early developmental lesions and thalamic lesions than a comparable control population.

See p. 1721; Editorial, p. 1708

Rising incidence of multiple sclerosis in females associated with urbanization

Spanning 3 decades, this case-control study of a genetically stable population identified factors introduced by urbanization that contributed to the increased incidence of multiple sclerosis (MS) among women. Linkage of MS to specific environmental changes may provide clues to disease etiology and prevention.

See p. 1728

IgA NMDA receptor antibodies are markers of synaptic immunity in slow cognitive impairment

Twenty-four patients with slowly progressive cognitive impairment had an underlying synaptic autoimmunity that decreased the density of NMDAR and other synaptic proteins and altered synaptic currents. In serum and CSF there were NMDAR IgA antibodies, thereby identifying possible candidates for immunotherapy.

See p. 1743
From editorialists Pittock \& Balice-Gordon: “. . . this study establishes that clinicians and scientists involved in characterizing novel autoantibody markers of disease should consider shifting from the historic focus on IgG alone to include other immunoglobulin classes."

See p. 1710

Occupational solvent exposure and cognition: Does the association vary by level of education?

The authors examined lifetime exposure to 4 solvent types (chlorinated solvents, petroleum solvents, benzene, and nonbenzene aromatic solvents) in retired utility workers using a validated job-exposure matrix. Solvent exposure was associated with poor cognition only among less-educated individuals. Higher cognitive reserve in the more-educated group may explain this finding.

See p. 1754

Family history of Alzheimer disease predicts hippocampal atrophy in healthy middle-aged adults

The authors analyzed 4-year longitudinal neuroimaging data from 108 cognitively healthy adults. Their findings suggest that the prevailing theoretical model of the Alzheimer disease (AD) pathophysiologic cascade-wherein brain atrophy is a later event, occurring closer to the manifestation of clinical AD-may be expressed differently in persons with a family history of $A D$. See p. 1769

Cognitive effects of one season of head impacts in a cohort

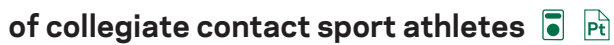

This study compared 214 football and ice hockey players who wore instrumented helmets that recorded the acceleration-time history of head impacts with 45 noncontact sport athletes. Few cognitive differences were found between the groups at preseason or postseason assessments; however, a subgroup of the contact athletes performed worse than predicted on a learning test.

See p. 1777, Editorial, p. 1712

NB: "Resident \& Fellow Journal Club: Intrathecal effects of daclizumab treatment of multiple sclerosis," see p. e131. To check out other Resident \& Fellow submissions, point your browser to www.neurology.org and click on the link to the Resident \& Fellow Section.

Podcasts can be accessed at www.neurology.org 


\section{Neurology}

Spotlight on the May 29 Issue

Robert A. Gross

Neurology 2012;78;1705

DOI 10.1212/WNL.0b013e318258760a

\section{This information is current as of May 28, 2012}

\section{Updated Information \&} Services

Permissions \& Licensing

Reprints including high resolution figures, can be found at: http://n.neurology.org/content/78/22/1705.full

Information about reproducing this article in parts (figures,tables) or in its entirety can be found online at:

http://www.neurology.org/about/about_the_journal\#permissions

Information about ordering reprints can be found online:

http://n.neurology.org/subscribers/advertise

Neurology ${ }^{\circledR}$ is the official journal of the American Academy of Neurology. Published continuously since 1951, it is now a weekly with 48 issues per year. Copyright Copyright $@ 2012$ by AAN Enterprises, Inc.. All rights reserved. Print ISSN: 0028-3878. Online ISSN: 1526-632X.

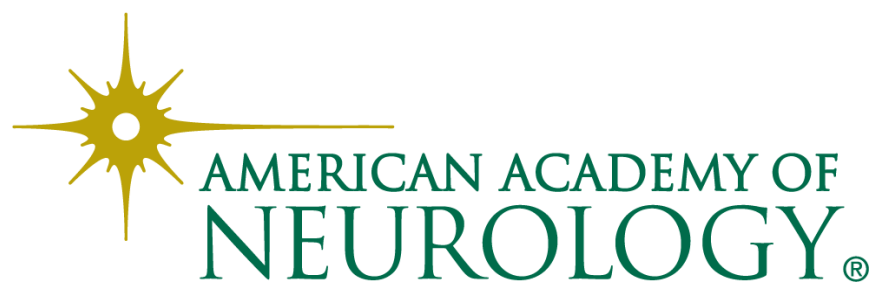

